\title{
BALLISTOCARDIOGRAMS AFTER CIGARETTE SMOKING IN HEALTH AND IN CORONARY HEART DISEASE
}

\author{
BY \\ C. B. HENDERSON* \\ From the Department of Therapeutic Research, University of Pennsylvania, Philadelphia, and the Regional \\ Cardiovascular Department, General Hospital, Newcastle-upon-Tyne
}

Received November 28, 1952

It has long been known that smoking precipitates anginal attacks in certain patients subject to this disorder, but this occurs only rarely. Smoking also causes changes in the pulse rate and blood pressure of many people (Roth, 1951) and in the electrocardiogram of a few (Evans and Stewart, 1943; Graybiel et al., 1938; and Wilson and Johnston, 1939), some subjects being unusually susceptible to the agent while others are affected little if at all.

Although it is agreed that if smoking precipitates cardiac pain the patient should not smoke, clinical experience with the effect of smoking on other cases of angina has not been sufficiently striking to make most doctors deprive their patients with coronary disease of this comforting habit; although, in the related arteriosclerotic condition of peripheral vascular disease the advice that such patients should stop smoking is now given routinely in many clinics. Because of the irregularity of the effect of nicotine on both healthy persons and those with cardiac disease, one is challenged to ascertain whether the heart of the patient before him is unusually susceptible to its effects or not, and to use this information as the basis for a decision regarding tobacco.

The ballistocardiograph has seemed particularly fitted to throw light on this problem, and it was employed for the purpose soon after instruments of this type became available in the clinic. Boyle et al. (1947) and Levy et al. (1946 and 1947) studied both the effect of smoking and of intravenous injection of nicotine itself on healthy persons and patients subject to coronary disease, using the Nickerson low frequency, damped ballistocardiograph (Nickerson, 1945) and making the more usual clinical measurements as well.

The results were irregular, some subjects of both healthy and cardiac groups showing marked changes of blood pressure, pulse rate, and the electrocardiogram after exposure to nicotine, but many others being affected little if at all. The cardiac output, calculated from the ballistocardiogram increased occasionally, but more often remained unchanged; and alterations in ballistic contour were not reported. The averages showed no significant difference between the circulatory dynamics of the response to nicotine in the two groups, but pain was produced in a few patients with coronary disease, and the electrocardiographic changes led to the conclusion that nicotine sometimes induced coronary insufficiency, either by coronary constriction or by increasing the work of the heart.

Using a different form of ballistocardiograph, the Dock portable direct-body type, Caccese and Schrager (1951) obtained more striking evidence of cardiac effects, for they demonstrated that changes of ballistic contour occurred after smoking in 18 of 31 subjects. Soon after, Mandlebaum and Mandlebaum (1952), using a ballistocardiograph of the same type, confirmed these results by finding th $\mathrm{t} 28$ per cent of 50 apparently healthy persons between 16 and 60 years of age, with normal ballistocardiograms before smoking, developed an abnormality of ballistic form after smoking, while in patients with coronary disease, most of whom had abnormal

\section{*Working with a Nuffield Foundation Medical Fellowship}


records before smoking, increased abnormality occurred after smoking more than twice as often as in healthy subjects. These results suggested that the effect of smoking on the heart was greater than the profession had believed; that patients with coronary heart disease were more frequently susceptible than had been realized; and that susceptibility and its absence could readily be detected by the ballistocardiogram and used as a basis for a decision whether a given patient should smoke or not. Indeed, making the decision in this way, the Mandlebaums (1952) were well impressed by the clinical result obtained by forbidding tobacco to those patients whose ballistocardiograms deteriorated after smoking.

It therefore appeared that investigators using two types of ballistocardiographs differing in their construction had obtained different results, one instrument recording a change of contour after smoking in many subjects, while the other failed to detect it, although there was ample evidence of other nicotine effects. Because of the obvious importance of the problem, it seemed wise to study a larger series of cases using a third type of ballistocardiograph, the high frequency table (Starr et al., 1939), which has certain advantages over the other types. Therefore, experiments have been performed on the effect of cigarette smoking on 124 subjects, with results in general similar to those reported with the Dock-type instrument. So it seems evident that smoking produces, in a few persons judged to be healthy and in a much higher proportion of those having coronary disease, a striking though temporary change in the contour of the ballistocardiogram of a type readily judged abnormal because it is never seen in the records of healthy young adults.

\section{METHOD AND MATERIAL}

Seven hundred and forty-four ballistocardiograms were taken on 124 subjects. Fifty of the subjects were healthy adults from 20 to 40 years of age, and thirty were healthy adults from 40 to 60 years of age; most were doctors, nurses, or hospital technicians, but also included were a few persons referred to the hospital and found to be healthy. Forty subjects were patients judged to have coronary disease because of a history of angina of effort or an electrocardiogram characteristic of cardiac infarction or both; these patients were drawn from the wards and outpatient clinics of the University of Pennsylvania Hospital, where all had had a complete clinical study. Because of the likelihood of the development of coronary disease in such cases-two patients with idiopathic hypercholesterolæmia, one with Buerger's disease, and one with diabetes mellitus with hypertension were also studied.

All the ballistic tracings were optically recorded on a high-frequency, undamped, table ballistocardiograph, and limb lead II of the electrocardiogram was simultaneously recorded to time and identify the ballistic waves. Standardization of the ballistocardiogram, by measuring the displacement of the base line caused by a force of 280 grams, was performed frequently. The standard adjustment was a displacement of the record's base line of $1 \mathrm{~cm}$. by this force.

The test was conducted as follows. The subject came to the laboratory at least two hours after the last meal. After a rest period of at least 15 minutes the first ballistocardiogram was taken and at the end of the run the subject was asked to breathe deeply. The subject was then given a popular brand of American cigarette and told to smoke it in his accustomed manner, while he continued to lie on the table. After thus smoking for one minute, he desisted briefly while a second ballistocardiogram was taken and then continued smoking for four more minutes. Then a third ballistocardiogram was taken immediately, and a fourth, fifth, and sixth record at 5-minute intervals thereafter. Blood pressure was taken by the usual auscultatory method before each ballistocardiogram. The decision whether the patient inhaled or not was made both by observing him and asking his opinion.

The tracings were studied for gross changes in wave form, the heart rate was determined, and the height and breadth of the waves were measured. Cardiac force was estimated for all records and the Tanner formula (Tanner, 1949) was used to calculate the cardiac outputs of all records normal in form. The results were analysed statistically for significant differences between the 
response of the normal subjects of the two age groups and the patients; and between the responses of those who inhaled the smoke and those who did not. As abnormalities of wave form were present in 34 of the 40 patients with coronary disease either before or during smoking, the cardiac output changes could be calculated in only 6 of these patients.

\section{RESULTS}

Group A-Normal subjects between 20 and 40 years of age. Forty of this group inhaled the tobacco smoke and 10 did not. Table I shows the average percentage changes in heart rate, blood

TABLE I

Ballistocardiographic Changes Due to Smoking One Cigarette

\begin{tabular}{|c|c|c|c|c|c|c|c|c|c|c|c|c|c|}
\hline & & \multicolumn{4}{|c|}{ GROUP A } & \multicolumn{4}{|c|}{ GROUP B } & \multicolumn{4}{|c|}{ GROUP C } \\
\hline & & \multicolumn{2}{|c|}{$\begin{array}{c}\text { Inhaled } \\
\text { smoke } \\
\text { (40 subjects) }\end{array}$} & \multicolumn{2}{|c|}{$\begin{array}{c}\text { Did not } \\
\text { inhale smoke } \\
\text { (10 subjects) }\end{array}$} & \multicolumn{2}{|c|}{$\begin{array}{c}\text { Inhaled } \\
\text { smoke } \\
(20 \text { subjects) }\end{array}$} & \multicolumn{2}{|c|}{$\begin{array}{c}\text { Did not } \\
\text { inhale smoke } \\
\text { (10 subjects) }\end{array}$} & \multicolumn{2}{|c|}{$\begin{array}{c}\text { Inhaled } \\
\text { smoke } \\
\text { (33 subjects) }\end{array}$} & \multicolumn{2}{|c|}{$\begin{array}{c}\text { Did not } \\
\text { inhale smoke } \\
\text { (7 subjects) }\end{array}$} \\
\hline & & Mean & $\begin{array}{c}\text { S.D. } \\
\text { of mean }\end{array}$ & Mean & $\begin{array}{c}\text { S.D. } \\
\text { of mean }\end{array}$ & Mean & $\begin{array}{c}\text { S.D. } \\
\text { of mean }\end{array}$ & Mean & of mean & Mean & $\begin{array}{l}\text { S.D. } \\
\text { of mean }\end{array}$ & Mean & $\begin{array}{l}\text { S.D. } \\
\text { of mean }\end{array}$ \\
\hline Heart rate & .. & $+17 \cdot 2 \%$ & \pm 1.9 & $+2 \cdot 7 \%$ & $\pm 1 \cdot 1$ & $+6 \cdot 6 \%$ & $\pm 2 \cdot 1$ & $+1.9 \%$ & \pm 0.8 & $+12 \cdot 2 \%$ & \pm 2 & $-0.4 \%$ & $\pm 1 \cdot 2$ \\
\hline Systolic B.P. .. & .. & $+5 \cdot 4 \%$ & $\pm 1 \cdot 2$ & $+1.8 \%$ & $\pm 2 \cdot 4$ & $+5 \cdot 2 \%$ & \pm 0.9 & $-3 \cdot 4 \%$ & $\pm 1 \cdot 5$ & $+4.6 \%$ & $\pm 1 \cdot 5$ & $+1.7 \%$ & $\pm 1 \cdot 5$ \\
\hline Diastolic B.P. ... & $\ldots$ & $+7 \cdot 2 \%$ & $\pm 1 \cdot 4$ & $+1 \cdot 8 \%$ & $\pm 2 \cdot 5$ & $+8 \cdot 2 \%$ & \pm 0.4 & $-0.7 \%$ & \pm 2 & $+5 \cdot 5 \%$ & $\pm 1 \cdot 8$ & $+2 \cdot 5 \%$ & $\pm 1 \cdot 3$ \\
\hline Cardiac output/min. & .. & $+13 \cdot 7 \%$ & $\pm 1 \cdot 9$ & $-0.4 \%$ & $\pm 1 \cdot 7$ & $+2 \cdot 2 \%$ & $\pm 3 \cdot 6$ & $-1.9 \%$ & $\pm 2 \cdot 1$ & $+2.5 \%$ & $\pm 2 \cdot 5$ & $-9 \%$ & $\pm 4 \cdot 5$ \\
\hline Cardiac strength & . & $-1.9 \%$ & \pm 2 & $-2 \cdot 7 \%$ & \pm 3 & $-6 \cdot 1 \%$ & $\pm 2 \cdot 7$ & $-12 \cdot 3 \%$ & $\pm 3 \cdot 3$ & $-9.8 \%$ & $\pm 3 \cdot 2$ & $-10.5 \%$ & $\pm 3 \cdot 7$ \\
\hline Wave form change & .. & \multicolumn{2}{|c|}{$0 \%$} & \multicolumn{2}{|c|}{$0 \%$} & \multicolumn{2}{|c|}{$15 \%$} & \multicolumn{2}{|c|}{$10 \%$} & \multicolumn{2}{|c|}{$39 \%$} & \multicolumn{2}{|c|}{$28 \%$} \\
\hline $\begin{array}{l}\text { Increased IJ respirator } \\
\text { variation }\end{array}$ & & \multicolumn{2}{|c|}{$32 \cdot 5 \%$} & \multicolumn{2}{|c|}{$10 \%$} & \multicolumn{2}{|c|}{$30 \%$} & \multicolumn{2}{|c|}{$20 \%$} & \multicolumn{2}{|c|}{$45 \%$} & \multicolumn{2}{|c|}{$43 \%$} \\
\hline
\end{tabular}

Group A consists of 50 healthy persons aged $20-40$ years. Group B, 30 healthy persons aged $40-60$ years, and Group C patients with coronary heart disease. The figures given in the "form change" and "increased respiratory variation" columns are the percentages of the number in that group showing such ballistocardiographic changes.

pressure, cardiac force, and cardiac output and the standard deviations of the means both in those who inhaled and in those who did not. The resting ballistocardiogram of each subject was normal, and in no cases did the record become abnormal in form after smoking. In 14 subjects (28\%) there was an increase in the respiratory variation of the ballistic waves, illustrated by Fig. 1A, which doubtless accompanied the deeper breathing that occurs during smoking.

Group B-Normal subjects between 40 and 60 years of age. Of the 30 persons in this group, 20 inhaled and 10 did not. Table I shows the average percentage changes in heart rate, blood pressure, cardiac force, and cardiac output and the standard deviations of the means. All the initial ballistocardiograms were normal in form, but four subjects developed abnormalities of form after smoking. In three of the four positive tests the subjects, all of whom inhaled the smoke, experienced tingling of the extremities, nausea, and vertigo, so that the unduly severe cardiac response was accompanied by other manifestations of unusually severe nicotine action. An example of the change of wave form is shown by Fig. 1B. In 8 persons (27\%) including the four who developed wave abnormalities, there was an increase in the respiratory variation of the ballistocardiogram after smoking.

Group C-Subjects with coronary heart disease. Of this group, 33 inhaled the tobacco smoke and 7 did not. Table I shows the average percentage changes in heart rate and blood pressure of the whole group, and the changes in cardiac force and cardiac output and the standard deviations of the means in the 6 patients (all inhalers of smoke) whose values could be calculated from the records. The initial ballistocardiograms of 19 patients were normal and 21 were abnormal. Ten of the 19 patients with normal initial tracings developed abnormalities of form, and 5 of the 21 patients with abnormal initial tracings developed more severe abnormalities after smoking. Thirteen 
of the 15 patients with positive tests inhaled the smoke. Fig. 1C and all the tracings in Fig. 2 illustrate the records obtained. An increase in the respiratory variation developed in 13 of the 15 patients with positive tests and in an additional 5 patients who showed no change in wave form after smoking.

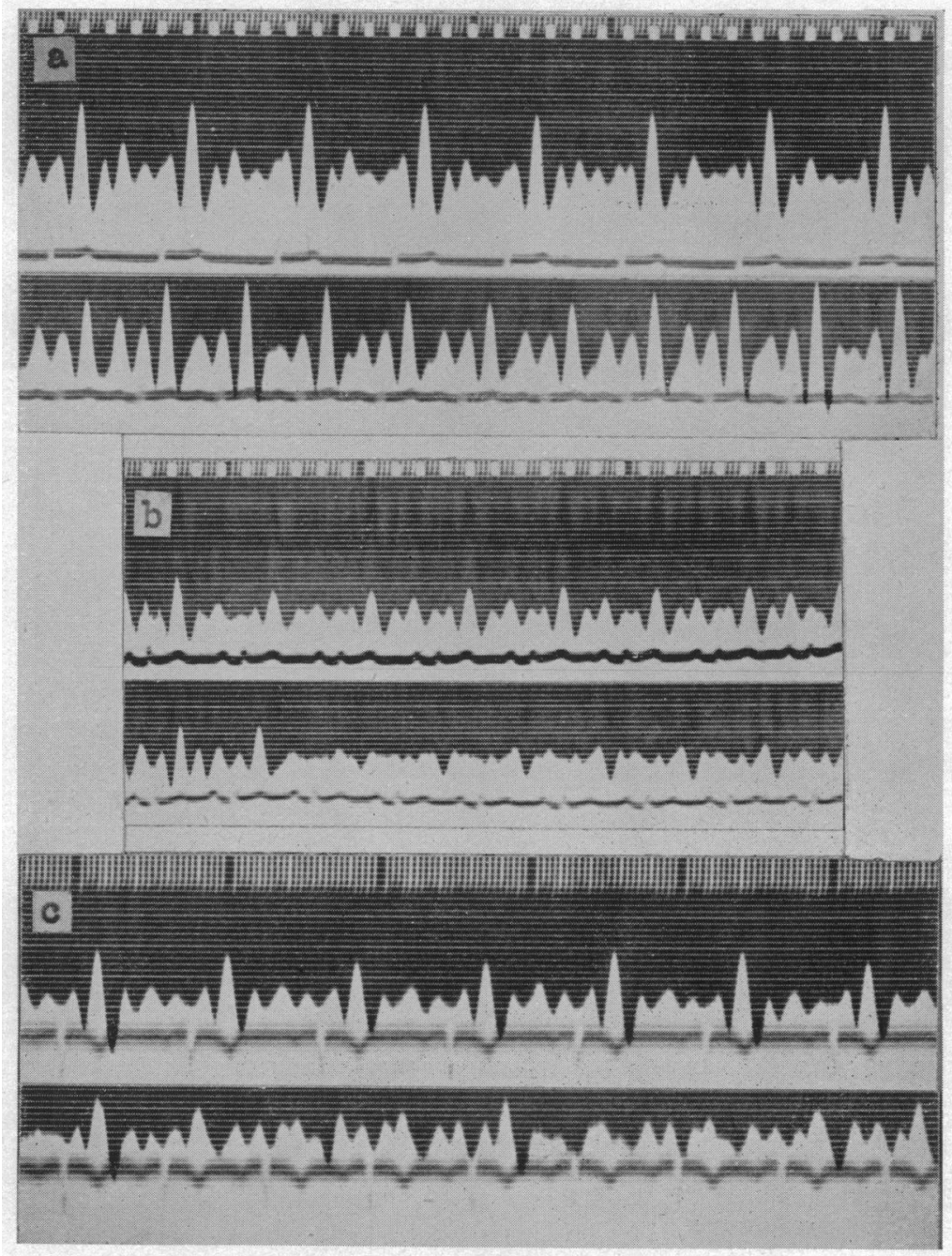

FIG. 1.-The effect of smoking on the ballistocardiogram with lead II cardiogram. The time record is at the top of each set of tracings and applies to the two records below. The time interval between the thick black lines is 1 second. The tracings are natural size. (a) R.S., aged 32 years. Normal cardiovascular system. BP. 125/70; heart rate 72/min.; E.C. normal. Upper control record is normal. Next record taken immediately after the subject has been smoking for 5 minutes; BP. 140/85; heart rate 102/min. Record normal, but IJ respiratory variation increased. (b) C.P., aged 44 years. Normal cardiovascular system. BP. 120/80; heart rate 80/min.; E.C. normal. Upper control record is normal. Next record after smoking for 5 minutes; BP. 140/100; heart rate 90/min. Record abnormal; I small and J small and deformed in the expiratory complexes. The IJ respiratory variation is increased. (c) R.B., aged 45 years. Angina of effort for 4 months. BP. 105/70; heart rate 70/min.; E.C. normal (the inversion of the cardiogram shown is due to incorrect lead attachments). Upper control record is normal. Next record after smoking for five minutes; BP. 110/80; heart rate 86/min. Record abnormal; complexes irregular in form, I small and frequently above the base line and $\mathrm{J}$ tiny and deformed in the expiratory complexes. The $\mathrm{IJ}$ respiratory variation is increased. The tracing, taken 15 minutes after smoking in each case, was normal and has not been reproduced. 
Group D-Miscellaneous cases. This group consisted of two patients with idiopathic hypercholesterolæmia who were considered otherwise healthy, one patient with Buerger's disease, and one with diabetes mellitus and hypertension. The initial ballistocardiogram of the case of Buerger's disease was abnormal, those of the other cases were normal. After smoking, each of the patients showed deterioration of wave form. Fig. 3A and 3B illustrate the records taken from the cases of hypercholesterolæmia and Fig. 3C from the case of Buerger's disease.

Effects due to inhaling the smoke. The data given in Table I show that changes in the cardiovascular dynamics occurred among those who inhaled the smoke, to a degree not found in those who did not inhale, as was certainly to be expected. This was true of all the groups studied, although the type and degree of change varied somewhat from group to group. In the healthy young persons, Group A, the average increase in pulse rate and estimated cardiac output was significantly greater in those who inhaled, but the blood pressure changes were not significantly different. In those older, healthy persons, Group B, the averages differed in the same direction, but the differences were not statistically significant. Again, in the coronary heart disease group, Group C, the average increase in heart rate was significantly higher in the smoke inhalers, but the blood pressure differences were not significant. Obviously, those who were judged to inhale the smoke exhibited greater responses to smoking than those judged not to inhale it.

Alteration of ballistic size. When the ballistocardiogram was normal in form the effect of smoking on its amplitude was not conspicuous in the young people, but amplitude diminished after smoking in both the older, healthy subjects, and the coronary group. The average diminution in the estimate of cardiac strength based on the vertical I-J distance (Starr et al., 1950) gives evidence of this. The increase of cardiac output as estimated from the ballistocardiogram was conspicuous only among the smoke inhalers of the younger group, and the changes found there were due to changes in heart rate.

Alteration in ballistic contour. When such alterations occurred after smoking, they were usually very conspicuous, as Fig. 1, 2, and 3 show clearly. Detailed description of a ballistic abnormality of form is never easy because the contour so often changes from beat to beat within the respiratory cycle, nevertheless, several types deserve attention. In the 23 tests in which ballistic form became abnormal after smoking, the systolic ballistic waves were affected in several combinations.

Fig. 2.-The effect of smoking on the ballistocardiogram. Record slightly reduced in size. (a) J.A., aged 45 years. Angina of effort for two years. BP. 160/80; heart rate 72/min.; E.C. normal. Upper control record is abnormal -I is tiny and slurred during expiration and the IJ respiratory variation is abnormally large. Next record after smoking for 5 minutes; BP. 180/90; heart rate $86 / \mathrm{min}$. Record more abnormal-nadir of I above the base line and $J$ tiny and deformed. (b) W.S., aged 54 years. Angina of effort for 3 years. B.P. 170/105; heart rate $82 / \mathrm{min}$. ; E.C. normal. Upper control record is abnormal-J waves are deformed and $\mathbf{H}$ waves equal the $\mathrm{J}$ waves in height in some small complexes. Second record after smoking for 5 minutes; BP. 170/95; heart rate $110 / \mathrm{min}$. Record more abnormal-H waves are much larger and the $\mathrm{J}$ waves more deformed. Third record, 15 minutes after smoking; BP. 180/100; heart rate 104/min. Record still grossly abnormal. (c) C.D., aged 39 years. Angina of effort for 6 months and known hypertensive for 6 years. BP. 220/120; heart rate 84/min.; E.C. abnormal. Upper control record abnormal-I waves small. Next record after smoking for 5 minutes; BP. 240/130; heart rate $110 / \mathrm{min}$. Record more abnormal-H and I waves smaller and $K$ waves larger. The tracings taken 15 minutes after smoking in (a) and (c) had reverted to the control form and have not been reproduced.

FIG. 3.-The effect of smoking on the ballistocardiogram. Record slightly reduced in size. (a) J.B., aged 39 years. Idiopathic hypercholesterolæmia-blood cholesterol $620 \mathrm{mg}$. Normal cardiovascular system. BP. 100/60; heart rate 66/min.; E.C. normal. Upper control record is normal. Next record after smoking for 5 minutes; BP. 115/70; heart rate 68/min. Record abnormal- $H$ wave increased in height and $J$ wave smaller than $H$, and deformed in some complexes. (b) F.F., aged 30 years. Idiopathic hypercholesterolæmia-blood cholesterol $700 \mathrm{mg}$. Normal cardiovascular system. BP. 120/80; heart rate 74/min.; E.C. normal. Upper control record is normal. Next record after smoking for 5 minutes. BP. 125/80; heart rate $78 / \mathrm{min}$. Record abnormal-I waves smaller during expiration, and the IJ respiratory variation is abnormally large. (c) C.M., aged 25 years. Buerger's disease for 3 years. Amputation of right great toe. BP. 150/95; heart rate 92/min.; E.C. abnormal. Upper control record is normal. Second record after smoking for 5 minutes. BP. 170/100; heart rate 120/min. Record grossly abnormal-I waves small, and J waves small and deformed during expiration. Third tracing, 15 minutes after smoking; BP. 150/95; heart rate 104/min. Tracing still grossly abnormal. The tracings taken 15 minutes after smoking in (a) and (b) had reverted to normal and have not been reproduced. 
A combination of $I$ and $J$ wave abnormalities occurred in 10 cases of coronary disease, 4 normal subjects in the 40 to 60 age group, the one with Buerger's disease, and one with idiopathic hypercholesterolæmia. The abnormalities consisted of a decrease in the depth of the I wave, in some complexes the nadir of the wave being above the base line, and a decrease in height and deformity of the $J$ wave. The changes were greatest in the small expiratory complexes. Examples of these abnormalities are shown in Fig. 1B and C, 2A, and 3B and C.

A combination of $\mathrm{H}$ and $\mathrm{J}$ wave abnormalities occurred in four cases of coronary disease, one with idiopathic hypercholesterolæmia, and in the one with diabetes mellitus. There was an increase in the height of the $\mathrm{H}$ wave as measured from the base line and the $\mathrm{J}$ waves became deformed or smaller than the $\mathrm{H}$ waves in some of the expiratory complexes. These types of abnormalities are illustrated by Fig. $2 \mathrm{~B}$ and $3 \mathrm{~A}$.

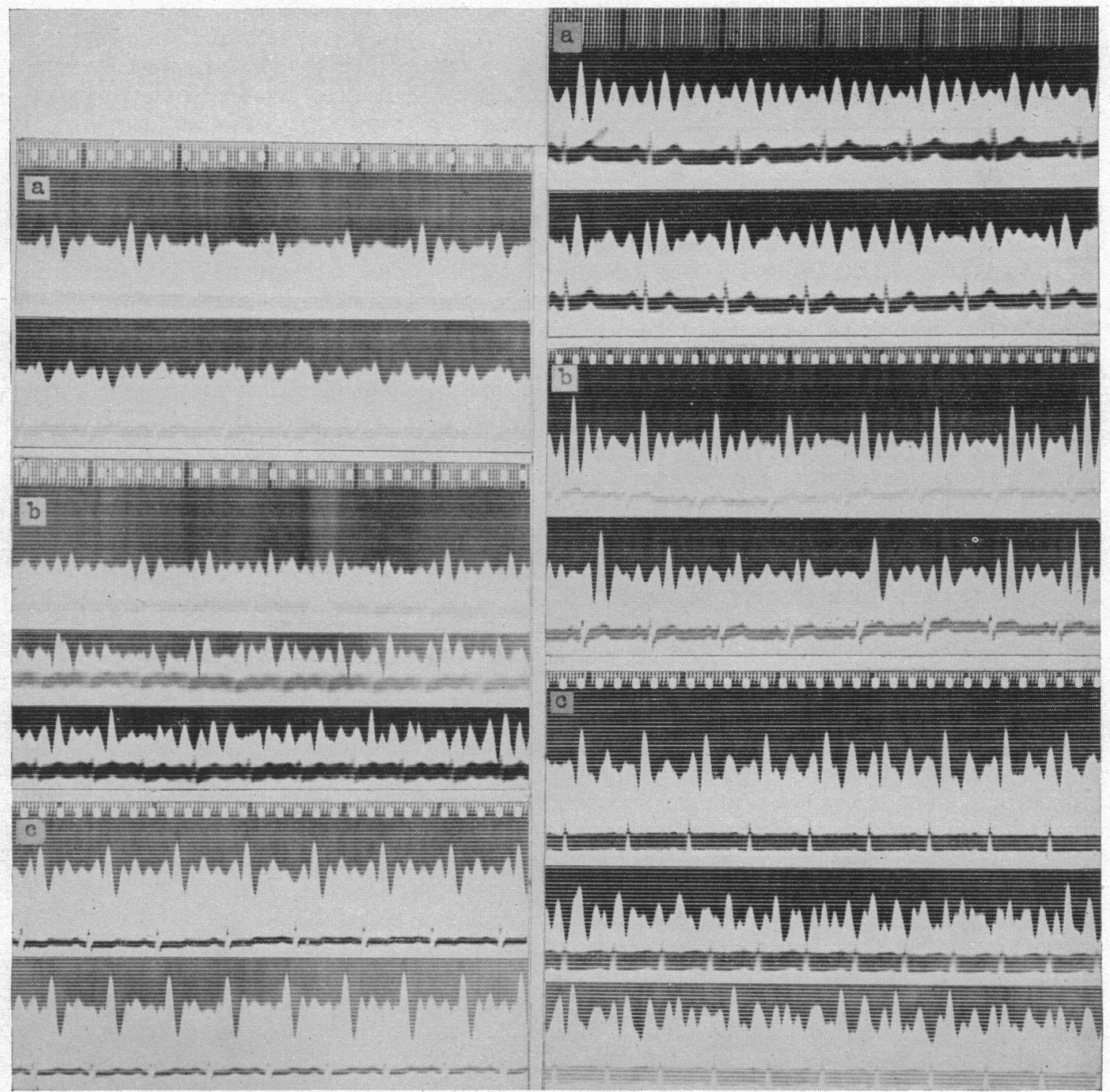

FIG. 2

FIG. 3 
A combination of $\mathrm{H}, \mathrm{I}$, and $\mathrm{K}$ wave abnormalities occurred in one patient with coronary heart disease and hypertension. In all phases of respiration the $H$ and $I$ waves decreased and the $K$ wave increased in size (Fig. 2C).

Duration of the abnormalities after smoking. In most cases the form of the ballistocardiogram reverted to its pre-smoking state within 5 minutes after the cessation of smoking. In a few instances, however, the abnormalities persisted longer than 15 minutes as shown by Fig. 2B and 3C.

\section{Discussion}

The results show clearly that smoking a single cigarette has a temporary influence on the myocardial function of certain persons, as judged by the contour of the ballistocardiogram. Healthy persons under 40 are not thus affected, although the increased heart rate, the average significantly greater than in older persons, indicates that nicotine was indeed exerting its usual action. In older persons, however, even though they seemed healthy, this myocardial effect is seen occasionally, and in those with coronary heart disease it is seen in about one-third of the cases. The few patients tested who, without symptoms or signs suggesting coronary disease, were suffering from conditions in which coronary disease is a frequent complication, all showed abnormality of myocardial function after smoking. Obviously, therefore, tobacco exerts an effect on the myocardium more frequently in those with coronary disease than in healthy persons; the difference is statistically significant in my data.

The nature and significance of this effect deserves discussion. Abnormal ballistic patterns of the type encountered after smoking have never been seen in records from the hundreds of healthy young adults who have been tested in this laboratory. Patterns resembling those seen after smoking have been encountered in persons suffering from advanced heart disease as diagnosed by the usual clinical criteria. It seems likely, therefore, that the effect of tobacco on the myocardium of the susceptible subject must be regarded as deleterious.

Smoking is well known to increase respiration, blood pressure, and heart rate, and it is proper to ask the question whether the myocardial effect detected could be secondary to any of these changes. The evidence is against this possibility. Every subject was asked to take a deep breath at the end of his control tracing and in no instance were abnormalities of contour, similar to those seen after smoking, encountered. Nor is there any regular relation between these abnormalities and blood pressure or pulse rate changes. The deterioration of wave form was associated with an increase in heart rate and blood pressure in 11 of the 23 positive tests, with no change in six tests, with an increase of blood pressure alone in four tests, and with an increase in heart rate alone in two tests.

The ballistic waves that deteriorated in form after smoking are in most cases those associated with cardiac contraction and ejection of blood into the great vessels, i.e. $H, I$, and J. waves, thus suggesting a change in the character of contraction and of ejection. The evidence indicates that this change is not solely the result of an increase of cardiac work, which overtaxes myocardial capacity, as six subjects with positive tests had no change in heart rate or blood pressure when the waves became abnormal, and in several others the ballistocardiogram reverted to normal when the heart rate and blood pressure were still elevated; nevertheless, it should be pointed out that increase in calculated cardiac output per minute, or increase in blood pressure, or both, did accompany the ballistic abnormality in many instances, so increased heart work might often have been a factor in producing a relative ischæmia.

A more probable primary mechanism is that of coronary vasoconstriction. This conception is supported by the character of the abnormalities of electrocardiographic wave form produced occasionally by smoking (Wilson and Johnston, 1939) which is often similar to that frequently seen in patients with cardiac infarction, and can be produced in animals whose coronary circulation has been interrupted. Coronary constriction was not demonstrated after nicotine in the older 
animal experiments designed to test the point (Sollman, 1948), and this is also true in still unpublished data (Eckenhoff, personal communication) secured by more modern methods (Eckenhoff et al., 1947). The results of the experiments of Burn (1951) indicate, however, that smoking leads to an outpouring of pituitary hormones which are well known to produce coronary vasoconstriction. This evidence therefore supports the view that coronary vasoconstriction is the explanation of the cardiac effects seen after smoking in my subjects.

But whatever the exact mechanism, the incidence of myocardial abnormality after smoking found in patients with coronary heart disease is far greater than that found in healthy persons in the older age group; this difference is statistically significant, and it indicates that pre-existing coronary artery disease enhances the deleterious effect of smoking on cardiac contraction. Fifteen of the subjects who had positive smoking tests had coronary heart disease and the remaining 8 were either in the 40 to 60 age group or suffered from diseases well known to predispose towards coronary heart disease, e.g. idiopathic hypercholesterolæmia, Buerger's disease, and diabetes mellitus. It is interesting to speculate whether in the latter eight patients the effect of nicotine exposed a latent coronary artery disease.

In the present series of cases, tobacco smoking adversely affected cardiac function in 38 per cent of the people with clinical evidence of coronary heart disease. If, as Mandlebaum and Mandlebaum (1952) have reported, the symptoms of such patients are considerably improved by abstention from smoking, then the result of this test is important in deciding the subsequent management of the patient.

\section{SUMMARY}

A study has been made of the effect of smoking a single cigarette on the cardiovascular dynamics of healthy persons and of patients with evidence of coronary heart disease, using a high-frequency ballistocardiograph.

In 50 healthy young persons, although there was a considerable increase in average pulse rate after smoking, the form of the ballistocardiogram remained normal in every case.

In 30 older persons believed to be healthy, a temporary abnormality of the ballistocardiogram. followed smoking in 4 instances.

In 40 patients with clinical evidence of coronary heart disease, the ballistocardiogram became abnormal or more abnormal in form after smoking in 15, or 38 per cent. In four patients without clinical evidence of coronary heart disease, but suffering from diseases in which coronary heart disease is a frequent complication, smoking caused ballistic abnormalities in all.

Unusual cardiac sensitivity to nicotine is readily detected by the ballistocardiogram, and it is found more frequently in cardiac patients than has been generally realized. The significance of this finding is discussed.

I am deeply indebted to Dr. Isaac Starr, Professor of Therapeutic Research, University of Pennsylvania Hospital, Philadelphia, U.S.A., for his guidance during the year I worked in his laboratory and for the considerable assistance: which he gave to me in the preparation of this paper.

\section{REFERENCES}

Boyle, M. N., Wegria, R., Cathcart, R. T., Nickerson, J. L., and Levy R. L. (1947). Amer. Heart J., 34, 65. Burn, J. H. (1951). Brit. med. J., 2, 199.

Caccese, A., and Schrager, A. (1951). Amer. Heart J., 42, 489.

Eckenhoff, J. E., personal communication.

L, Hafkenschiel, J. H., and Landmesser, C. M. (1947). Amer. J. Physiol., 148, 582.

Evans, W. F., and Stewart, H. J. (1943). Amer. Heart J., 26, 78.

Graybiel, A., Starr, R. S., and White, P. D. (1938). Amer. Heart J., 15, 89.

Levy, R. L., Boyle, M. N., Wegria, R., Cathcart, R. T., and Nickerson, J. L. (1946). Tr. Ass. Amer. Physicians, $59,177$. -, Mathers, J. A., Muller, H. A., and Nickerson, J. L. (1947). J. Amer. med. Ass., $135,417$.

Mandlebaum, H., and Mandlebaum, R. A. (1952). Circulation, 5, 885. 
Nickerson, J. L. (1945). Fed. Proc., 4, 201.

Roth, G. M., Mod. Concepts Cardiovasc. Dis., April, 1945, vol. 14, No. 4; May, 1945, vol. 14, No. 5. (1951). Tobacco and the Cardiovascular System. C. C. Thomas, Springfield, Ill.

Sollman, T. (1948). Pharmacology. 7th ed., W. B. Saunders, Phila., Pa.

Starr, I., Rawson, A. J., Schroeder, H. A., and Joseph, N. R. (1939). Amer. J. Physiol., $127,1$. Horwitz, O., Mayock, R. L., and Krumbhaar, E. B. (1950). Circulation, 1, 1073.

Tanner, J. M. (1949). J. Clin. Invest., 28, 567.

Wilson, F. N., and Johnston, F. D. (1939). Tr. Ass. Amer. Physicians, 54, 210. 